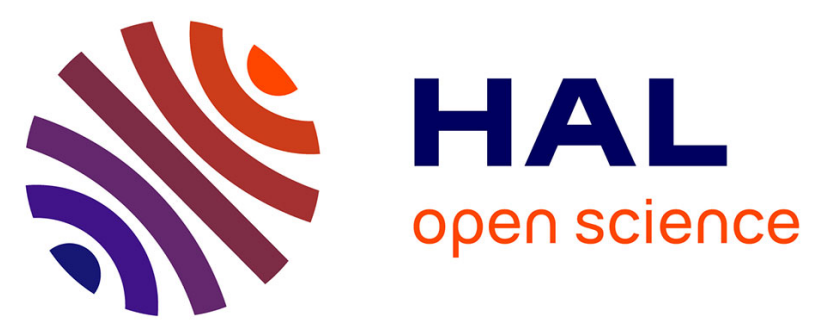

\title{
Predicting Nurses' Occupational Commitment and Turnover Intention: The Role of Autonomous Motivation and Supervisor and Coworker Behaviors
}

Claude Fernet, Nicolas Gillet, Stéphanie Austin, Sarah-Geneviève Trépanier, Sophie Drouin-Rousseau

\section{To cite this version:}

Claude Fernet, Nicolas Gillet, Stéphanie Austin, Sarah-Geneviève Trépanier, Sophie Drouin-Rousseau. Predicting Nurses' Occupational Commitment and Turnover Intention: The Role of Autonomous Motivation and Supervisor and Coworker Behaviors. Journal of Nursing Management, 2021, 29, pp.2611-2619. 10.1111/jonm.13433 . hal-03322598

\section{HAL Id: hal-03322598 \\ https://hal.science/hal-03322598}

Submitted on 19 Aug 2021

HAL is a multi-disciplinary open access archive for the deposit and dissemination of scientific research documents, whether they are published or not. The documents may come from teaching and research institutions in France or abroad, or from public or private research centers.
L'archive ouverte pluridisciplinaire HAL, est destinée au dépôt et à la diffusion de documents scientifiques de niveau recherche, publiés ou non, émanant des établissements d'enseignement et de recherche français ou étrangers, des laboratoires publics ou privés. 


\title{
Predicting Nurses' Occupational Turnover Outcomes: \\ The Role of Autonomous Motivation and Supervisor and Coworker Behaviors
}

\author{
Authors: \\ Claude FERNET, Ph.D. \\ Département de gestion des ressources humaines \\ Université du Québec à Trois-Rivières, Canada \\ Nicolas GILLET, Ph.D. \\ Département de psychologie, Université de Tours, France \\ Institut Universitaire de France (IUF) \\ Stéphanie AUSTIN, Ph.D. \\ Département de gestion des ressources humaines \\ Université du Québec à Trois-Rivières, Canada \\ Sarah-Geneviève TRÉPANIER, Ph.D. \\ Département de gestion des ressources humaines \\ Université du Québec à Trois-Rivières, Canada \\ Sophie DROUIN-ROUSSEAU, B.A. \\ Département de Psychologie \\ Université du Québec à Trois-Rivières, Canada
}

\section{Acknowledgements:}

Preparation of this paper was supported by grants from the Fonds de Recherche du Québec-Société et Culture (2019-SE1-252542)

\section{Conflict of interests:}

None of the authors have any conflict of interest to declare.

\section{Ethical Approval:}

Approval for this study (CER-10-159-06.20) was obtained from the Ethic Committee of the principal researcher's institution (Université du Québec à Trois-Rivières, Canada).

\section{Corresponding author:}

Claude Fernet, Ph.D.

Département de gestion des ressources humaines

École de gestion, Université du Québec à Trois-Rivières

3351 boul. des Forges, C.P. 500, Trois-Rivières, QC, Canada, G8Z 4M3

Email: claude.fernet@uqtr.ca

This is the prepublication version of the following manuscript:

Fernet, C., Gillet, N., Austin, S., Trépanier, S.-G., \& Drouin-Rousseau, S. (in press). Predicting nurses' occupational commitment and turnover intention: The role of autonomous motivation and supervisor and coworker behaviors. Journal of Nursing Management. Early view. https://doi.org/10.1111/jonm.13433

(C) 2021. This paper is not the copy of record and may not exactly replicate the authoritative document published in Journal of Nursing Management. 


\title{
Predicting Nurses' Occupational Commitment and Turnover Intention:
}

The Role of Autonomous Motivation and Supervisor and Coworker Behaviors

\begin{abstract}
Aim. To examine whether supportive supervisor (transformational leadership) and coworker (autonomy-supportive) behaviors predict occupational commitment and turnover intention over time through autonomous motivation.
\end{abstract}

Background. Nurse turnover is a serious issue in several countries, straining the efficiency of the healthcare system and compromising both the quality and accessibility of healthcare.

Method. Longitudinal data were collected over 12 months from 387 French-

Canadian registered nurses. Structural equation modelling was used to test the hypothesized model. Results: The relationships between predictors at Time 1 (supervisor and coworker behaviors) and occupational commitment and turnover intention at Time 2 are mediated by autonomous motivation at Time 1.

Conclusion: In times of global scarcity, the present findings provide insights into how the healthcare work environment acts on nurses' occupational turnover and commitment.

Implications for Nursing Management: Healthcare organizations are advised to foster supportive work environments and promote autonomous motivation to sustain the nursing workforce.

Keywords: Nurse turnover and retention, autonomous motivation, occupational commitment, transformational leadership, autonomy support 


\section{Introduction}

Although research has suggested for some time that nurse turnover is a serious concern in several countries (Perreira et al., 2018), most empirical studies have focused on inter-role transitions, such as organizational commitment, with less attention directed toward occupational turnover indicators including affective commitment and intention to leave the profession (Van Der Heijden et al., 2018). Yet, if staff turnover incurs significant direct costs (e.g., recruiting, replacement) as well as indirect costs (e.g., loss of productivity) for healthcare organizations, quitting the profession substantially adds to this burden, further straining the efficiency of the healthcare system and compromising both access to and quality of care and services (Hayes et al., 2012). This situation is all the more alarming given the global shortage of nurses and midwives which is estimated to reach nine million by 2030 (World Health Organization, 2020).

Several psychosocial factors have been associated with nurses' retention in the occupation. These factors generally fall into two categories, namely (1) work environment (e.g., supervisor and coworker support, job overload, lack of professional autonomy), and (2) individual (e.g., job attitudes, demographic characteristics such as age and job experience) factors (e.g., Pursio et al., 2021; Van Der Heijden et al., 2018). However, among the individual factors assessed, the role of autonomous motivation at work has not been clearly established. Yet, recent work (e.g., Fernet et al., 2020) suggests that nurses who emotionally disengage from their occupation previously experience a gradual decline in autonomous motivation, defined by self-determination theory (SDT; Ryan \& Deci, 2017) as the sense of being able to act according to their own choices, values, and interests. Despite this finding, research is currently limited as to the temporal relationship between nurses' autonomous motivation and occupational commitment and turnover intention. It remains unclear whether, and how, social work environment factors may contribute to nurses' occupational commitment and turnover intention over time. Turnover intention refers to a deliberate and conscious willingness to quit the occupation or the organization (Tett \& Meyer, 1993). As for commitment, it reflects nurses' emotional attachment, involvement and identification with the occupation (Meyer et al., 1993). In addition to being associated with significant organizational and societal costs (Douada et al., 2021; Hayes et al., 2012), these two variables are associated with actual turnover (Van Der Heijden et al., 2018). 
To address this issue, we tested a model which posits that nurses' perceptions of supportive behavior from their immediate supervisor and coworkers relate to their autonomous motivation at work, which simultaneously predicts greater affective commitment to the occupation and lower intention to leave it over time. This study offers three main research contributions. First, we address the need for research to improve our understanding of why nurses intend to leave the occupation (Baljoon et al., 2019). To date, research has primarily focused on motivational correlates (e.g., job satisfaction), rather than examining the underlying reasons for being fully engaged in the job (Fernet et al., 2017). The present longitudinal study allows us to address this gap by examining the temporal relationship between autonomous motivation and two well-established occupational turnover indicators (commitment and turnover intention). As the occupational turnover literature is largely based on cross-sectional evidence, we aimed to offer a more comprehensive understanding of the dynamic nature of nurses' autonomous motivation. Despite the relatively stable nature of occupational commitment and turnover intention (Fernet et al., 2020), this would suggest that autonomous motivation can produce a motivational drive that stimulates nurses to become more committed and less inclined to leave the profession over time. Second, we assess the contribution of the perceived behaviors of two key agents of the organization (i.e., immediate supervisor and coworkers) in the prediction of nurses' motivation. By drawing attention to the complementary and relative role of these agents' behaviors on work motivation (Jungert et al., 2020), this research suggests different avenues for intervention with nurses. Third, this study allows us to better understand the psychological mechanisms involved in occupational commitment and turnover intention. By proposing autonomous motivation as an explanatory mechanism, we advance research by identifying psychological pathways by which the prevailing social context in health care organizations is liable to act on nurses' occupational turnover over time.

\section{Theoretical Background}

\section{Autonomous Motivation}

SDT (Ryan \& Deci, 2017) provides a useful framework for understanding nurses' motivation. Focusing on both the quantitative and qualitative aspects of motivation, SDT distinguishes two main forms of motivation: Autonomous and controlled. In autonomous motivation, an effort is made for the 
pleasure and satisfaction of performing the task (intrinsic motivation) or because it allows for the attainment of objectives aligned with one's personal values (identified regulation). In contrast, controlled motivation refers to efforts made in response to internal (introjected regulation; avoiding anxiety or guilt or achieving a sense of self-worth) or external (external regulation; avoiding constraints or obtaining material or social rewards) pressures. In the present study, we focus on autonomous motivation, as it is more sensitive than controlled motivation to work environment factors (Fernet et al., 2015) and is a better predictor of change in attitudes at work (e.g., commitment, turnover intention; Austin et al., 2020).

\section{Social Work Environment Predictors of Autonomous Motivation}

According to SDT, employee motivation is largely influenced by environmental conditions in the workplace including the interpersonal work climate (Gagné \& Deci, 2005). An environment that provides conditions supporting employees' growth and development contributes to their autonomous motivation (Ryan \& Deci, 2017). Research has shown that supportive behaviors, both from the immediate supervisor and coworkers in the form of leadership or autonomy support, can facilitate employees' autonomous motivation (Jungert et al., 2020).

Supportive supervisor behaviors. Transformational leadership theory (Bass, 1985) arguably provides one of the best-established conceptualizations of supportive supervisor behaviors in the nursing context (Cummings et al., 2018). This framework is based on four types of behavior: Idealized influence (serving as role model), inspirational motivation (inspiring others to become fully committed to organizational goals), intellectual stimulation (encouraging others to be creative and innovative), and individualized consideration (providing a supportive climate, paying attention to each nurse's needs). Several studies support the effect of an immediate supervisor's transformational leadership behaviors on nurses' autonomous motivation (e.g., Fernet et al., 2015). These behaviors promote autonomous motivation as they create the conditions required for the satisfaction of basic psychological needs (Ryan \& Deci, 2017) and for the appropriation of work resources conducive to performance (e.g., Fernet et al., 2015). The theory and available findings lead us to propose the following hypothesis: 
Hypothesis 1. Supportive supervisor behaviors at Time 1 are positively associated with nurses' autonomous motivation at Time 1 .

Supportive coworker behaviors. Although research in the nursing context has focused more on the leadership behaviors of the immediate supervisors, the behaviors of coworkers likely play an important role in motivating nurses (e.g., Jungert et al., 2020) for two main reasons. First, the reality of many healthcare organizations, particularly in a context of a shortage, leads them to orient their management strategies towards the achievement of specific results, such as accessibility and quality of services, thus promoting task-focused leadership (Cummings et al., 2018). This approach leaves immediate supervisors with fewer opportunities and time to support, coach, and motivate their team members (Shao et al., 2019). Second, the departments and units in which nurses operate generally rely on small teams to perform well, which makes collaboration and supportive behaviors essential for motivation and commitment (Galletta et al., 2019).

According to SDT (Ryan \& Deci, 2017), supportive coworker behaviors foster autonomous motivation by creating an environment conducive to communication, information sharing, and recognition. A nurse can help another by giving constructive comments that allow, for example, the colleague to grasp the meaningful rationale or the merits of a task (Reeve \& Cheon, 2016). A nurse can also respect a colleague's perspective, by being available to give information, clarify any ambiguities related to the position or task, answer questions, and offer guidance (Fernet et al., 2015). Jungert et al. (2020) have shown that such coworkers' autonomy-supportive behaviors enhance autonomous motivation (i.e. intrinsic motivation) of employees in a social occupational context. Although few studies have examined the relationship between autonomy-supportive behaviors from coworkers and nurses' autonomous motivation, the simultaneous consideration of supportive behaviors of the immediate supervisor and coworkers will provide insight into their relative contribution. We thus propose the following hypothesis:

Hypothesis 2. Supportive coworker behaviors at Time 1 are positively associated with nurses' autonomous motivation at Time 1 .

\section{Autonomous Motivation and Occupational Commitment and Turnover Intention}


Growing empirical evidence suggests that autonomous motivation at work promotes employee adaptation and functioning (Ryan \& Deci, 2017). In the nursing context, nurses' autonomous motivation has been correlated with a variety of job attitudes related to retention, including occupational commitment, and negatively correlated with the intention to leave the organization and the nursing profession (Fernet et al., 2017, 2020; Galleta et al., 2016). However, as past research has mainly utilized cross-sectional designs, little is currently known about the temporal relationship between motivation and occupational commitment and turnover intention.

Occupational affective commitment. Occupational affective commitment is a unique construct that captures the psychological relationship that nurses develop with their occupation (Van Der Heijden et al., 2018). The emotional attachment that nurses experience towards their profession allows them to maintain positive feelings towards their position and sustains their occupational commitment (Meyer et al., 1993). According to SDT, this level of emotional attachment is expected to depend on the reasons that led the nurses to invest in their occupation. When nurses' efforts are fully aligned with their choices and values (i.e., high autonomous motivation), this should strengthen their emotional attachment and commitment to their role. We thus propose the following hypothesis:

Hypothesis 3. Nurses' autonomous motivation at Time 1 positively predicts occupational affective commitment at Time 2.

Occupational turnover intention. As the intent to leave refers to the conscious and deliberate desire to quit the profession (Tett \& Meyer, 1993), it could stem from underlying reasons which motivate nurses to invest effort into their work (Fernet et al., 2017). Whereas autonomous motivation is characterized by volition and self-endorsement of choices and actions, nurses who do not find pleasure, satisfaction, or a genuine interest in performing tasks aligned with their personal values could be inclined to leave their occupation. According to Sheldon and Elliot (1999), the self-consistent nature of autonomously motivated activities is likely to create a sense of genuineness, which should allow autonomously motivated nurses to feel alive and authentic. Because they appreciate having the opportunity to express their true selves, autonomously motivated nurses would be more inclined to remain in the profession. Accordingly, we propose the following hypothesis: 
Hypothesis 4. Autonomous motivation at Time 1 negatively predicts occupational turnover intention at Time 2.

\section{The Mediating Role of Autonomous Motivation}

Implicit to all four hypotheses and in SDT (Ryan \& Deci, 2017) is the notion that supportive behaviors have an effect on occupational commitment and turnover intention through autonomous motivation. Despite the lack of empirical evidence in a nursing context, results from several organizational studies support this motivational sequence (see Ryan \& Deci, 2017). Thus, we explicitly predict a mediated model.

Hypothesis 5. Autonomous motivation at Time 1 mediates the relationships between perceived supportive supervisor and coworker behaviors at Time 1, and occupational commitment and turnover intention at Time 2.

\section{Method}

\section{Study Design and Sample}

The participants of this 12-month longitudinal study were French-Canadian registered nurses working in the public healthcare sector. Our sample was drawn from a random mailing list of 665 nurses, members of the Quebec Nursing Association who agreed to be contacted for academic research purposes. Eligibility criteria was limited to the ability to read and understand French. All participants were asked to provide informed consent, before completing each online questionnaire. They were informed about the objectives of the research, told that participation was voluntary and confidential, and notified that they could freely withdraw from the project at any time. Approval for this study was obtained from the Ethic Committee of the principal researcher's institution. Out of this list, 387 nurses took part in our survey either at T1 (May 2014; $n=302$ ) or T2 (May 2015; $n=206$ ) and represented the final sample (overall response rate: 58\%). Most participants were women (88.9\%; $n=344)$ and held a permanent position $(78.2 \% ; n=280)$ and $54.9 \%(n=196)$ worked full time. The mean sample age was 29.15 years $(S D=9.25)$ and average length of experience in nursing was 4.19 years $(S D=9.41)$.

\section{Measures}


All variables were administered in French at both time points with the exception of the predictors (supportive supervisor and coworker behaviors), which were assessed at Time 1 only (means, standard deviations, latent correlations are presented in Table 1). Validity and reliability of the FrenchCanadian version of these measures have been supported in prior studies (Fernet et al., 2017, 2020). For all variables, higher scores reflect greater levels of each corresponding construct.

Supportive supervisor behaviors. The seven-item Global Transformational Leadership scale (GTL; Carless et al., 2000) was used to assess nurses' perceptions of supportive leadership behaviors of their immediate supervisor ( $\alpha=.94$; "He/she fosters trust, involvement, and cooperation among team members"). Items were scored on a five-point scale ranging from "never" to "almost always".

Supportive coworker behaviors. A three-item adapted version of Blais et al.'s (1991) scale was used to assess autonomy-supportive behaviors from coworkers $(\alpha=.75)$. Participants were asked to rate on a seven-point scale from "do not agree at all" to "very strongly agree" the extent to which their colleagues interacted with them in a given way (e.g., "My colleagues provide me with constructive feedback regarding my work and help me improve it").

Autonomous motivation. Two dimensions of the Revised Motivation at Work Scale (R-MAWS; Gagné et al., 2015) were used to assess autonomous motivation (T1 $\alpha=.82 ; \mathrm{T} 2 \alpha=.87$ ): Intrinsic motivation (three items; e.g., "Because my work is stimulating") and identified regulation (three items; e.g., "Because this job has a personal significance for me"). Respondents scored on a seven-point scale from "not at all for this reason" to "exactly for this reason" the primary reasons for performing their job.

Occupational commitment. Three items adapted from Meyer et al. (1993) were used to assess affective occupational commitment ( $\mathrm{T} 1 \alpha=.85 ; \mathrm{T} 2 \alpha=.78)$. A sample item is "The nursing profession means a lot to me". Each item was scored on a five-point scale from "strongly disagree" to "strongly agree".

Occupational turnover intention. Three items adapted from O'Driscoll and Beehr (1994) were used to assess occupational turnover intention (T1 $\alpha=.88$; T2 $\alpha=.93$ ). A sample item is "I'm thinking about leaving the nursing profession". Each item was scored on a seven-point scale from "strongly disagree" to "strongly agree". 


\section{Statistical Analysis}

A series of models were tested through structural equation modeling using a robust maximum likelihood estimator (MLR) in Mplus 8.4 (Muthén \& Muthén, 2019). Full Information Maximum Likelihood (FIML) was used to handle missing data (e.g., Enders, 2010). To determine the goodnessof-fit of these models, various fit indices were used: The Comparative Fit Index (CFI), the TuckerLewis Index (TLI), and the Root Mean Square Error of Approximation (RMSEA). Values greater than .90 for the CFI and TLI and smaller than .08 for the RMSEA indicate acceptable fit (Marsh et al., 2005).

\section{Results}

\section{Preliminary Analysis}

Three measurement models were tested. The first model (M1a) consisted of all latent variables and indicators at Time 1 (supervisor and coworker behaviors, autonomous motivation, and occupational commitment and turnover intention), while the second model (M1b) included all latent variables and indicators at Time 2 (autonomous motivation, and occupational commitment and turnover intention). Both models presented satisfactory fit indices: $\chi^{2}(\mathrm{df})=427.735(199), \mathrm{CFI}=.923$, $\mathrm{TLI}=.911$, and RMSEA $=.062[.054 ; .070]$ for Model $1 \mathrm{a}$; and $\chi^{2}(\mathrm{df})=109.530(51)$, CFI $=.946$, TLI $=.930$, and RMSEA $=.066[.049 ; .084]$ for Model 1b. A third measurement model was tested $(\mathrm{M} 1 \mathrm{c})$ by combining all latent variables and indicators at both measurement times, and consisted of eight latent variables (i.e., autonomous motivation, and occupational commitment and turnover intention at Times 1 and 2, as well as supervisor and coworker behaviors at Time 1 only) and 34 indicators. Following previous recommendations (Little et al., 2007), each item at Time 1 was also allowed to covary with its corresponding item at Time 2 . Results indicated that this model presented a satisfactory fit to the data: $\chi^{2}(\mathrm{df})=851.693(487)$, CFI $=.926$, TLI $=.915$, and RMSEA $=.044[.039$; .049]. Parameter estimates are reported in Table 1 (latent correlations) and Table 2 (loadings and uniquenesses).

\section{Main Analysis}

The proposed model (see Figure 1) presented satisfactory fit to the data: $\chi^{2}(\mathrm{df})=895.721(499)$, $\mathrm{CFI}=.919, \mathrm{TLI}=.909$, and RMSEA $=.045[.041 ; .050]$. Supportive supervisor $(\beta=.162, p<.05)$ and 
coworker $(\beta=.465, p<.001)$ behaviors at Time 1 positively predicted autonomous motivation at Time 1. In addition, each of the following variables at Time 1 (autonomous motivation, and occupational commitment and turnover intention) were significantly and positively related to its corresponding variable at Time 2 ( $\beta$ s ranging from .445 to $.760, p<.001$ ). Finally, results show that controlling for baseline effects, autonomous motivation at Time 1 positively predicted occupational commitment at Time $2(\beta=.232, p<.01)$ and negatively predicted occupational turnover intention at Time $2(\beta=-.200, p<.05)$.

Bootstrapping analyses (Cheung \& Lau, 2008) were then conducted to analyze the mediating role of autonomous motivation at Time 1 in the relationships, on the one hand, between supportive supervisor and coworker behaviors at Time 1, and on the other hand, occupational commitment and turnover intention at Time 2 . The indirect effects were tested with $95 \%$ confidence intervals computed from 5000 bootstrap samples. First, the relationship between supportive supervisor behaviors at Time 1 and both outcomes at Time 2 was mediated by autonomous motivation at Time 1 (occupational commitment [indirect effect $=.069 ;$ s.e. $=.043 ; 95 \% \mathrm{CI}=.007$ to .183$]$ and turnover intention [indirect effect $=-.038$; s.e. $=.027 ; 95 \% \mathrm{CI}=-.122$ to -.004$]$ ]). Second, the relationship between supportive coworker behaviors at Time 1 and both outcomes at Time 2 was mediated by autonomous motivation at Time 1 (occupational commitment [indirect effect $=.199$; s.e. $=.089 ; 95 \% \mathrm{CI}=.055$ to .403 ] and turnover intention [direct effect $=-.109 ;$ s.e. $=.067 ; 95 \% \mathrm{CI}=-.293$ to -.012$]$ ).

\section{Discussion}

\section{Theoretical Implications}

The main contribution of this study is the identification of autonomous motivation as a dynamic individual factor that simultaneously acts on occupational commitment and turnover intention. The greater autonomous motivation the nurses show - investing in their work for pleasure and satisfaction or to achieve professional goals that they value - the more they will become affectively committed to their occupation and the less inclined they will be to leave it over time. While these results align with those of recent cross-sectional studies carried out within the nursing context (Fernet et al., 2017;

Galleta et al., 2016), they could constitute the first empirical evidence that nurses' autonomous motivation acts on occupational commitment and turnover intention over time. 
The present study also sheds new light on the predictors and occupational outcomes of nurses' autonomous motivation. First, our results show that supportive behaviors by both the immediate supervisor and coworkers relate to nurses' work autonomous motivation. By revealing the distinct and complementary contribution of these key agents in their environment, our results underline the need to consider the role of social resources separately (rather than as an aggregate variable, irrespective of the source; e.g., supervisor, coworkers). These findings lend additional support to recent Job DemandsResources model based-studies having shown the relative contribution of various job resources (Hakanen et al., 2021), including social support from the supervisor and coworkers in nursing studies (e.g., Van der Heijden et al., 2019). Whereas SDT-based research has heavily focused on supervisor behaviors, our results also invite to examine the contribution, not only of the immediate supervisor, but of other key agents in the work environment. Interestingly, the present findings are aligned with a recent experimental study (Jungert et al., 2020) showing that autonomy-supportive behaviors from coworkers increased autonomous motivation more than from a supervisor in a social occupational context.

\section{Limitations}

First, the study relies exclusively on self-report data that may be subject to self-presentation report bias. Future research integrating multi-source (e.g., coworker leadership assessment) and objective (e.g., actual turnover) data would increase the range of the results. Second, the study is based on a partial longitudinal design, which does not allow us to establish causal relationships between all the variables examined. Third, although we have relied on proven theoretical perspectives to determine predictors of autonomous motivation, our analysis relies on a limited set of predictors. Further research should enhance our understanding of predictors, especially the larger work environment, at various levels (e.g., organizational culture and climate, human resource practices). Finally, our study should be replicated in other countries with more heterogeneous samples (e.g., wider age range, racial and ethnic groups).

\section{Implications for Nursing Management}

From a social perspective, keeping nurses in the profession is a major concern given the current global shortage, but also in terms of associated societal issues (Duffield et al., 2014). The COVID-19 
pandemic context reminds us on the need to count on an adequate influx of healthcare personnel in order to maintain the efficiency of our healthcare systems. What emerges from our results is that nurses' occupational affective commitment (and the desire not to abandon it) can be cultivated within an establishment by certain key agents, for example through the supportive nature of relationships with the immediate supervisor and coworkers. Organizational efforts to strengthen nurses' autonomous motivation, through supportive supervisor and coworker behaviors, should prove to be a beneficial strategy for contributing to a well-rooted workforce in the profession.

Among the possible means to facilitate such efforts, healthcare managers, including supervisors in departments or units, could promote a culture of support, for example by encouraging equity in the application of policies and relying on shared leadership (Pursio et al., 2021). The finding that supportive coworker behaviors would be particularly important to facilitate nurses' autonomous motivation adds to the relevance of bringing particular attention to shared leadership in which team members with particular knowledge, skills or abilities assume greater leadership in some areas of their work. Coaching activities, as well as formal and informal mentoring, may also help to build a more supportive workplace climate for nurses (Newman et al., 2012). SDT has great potential in this regard, particularly for understanding the need-supportive conditions (e.g., autonomy support, appropriate structure and interpersonal involvement strategies) that facilitate optimal functioning and might therefore serve as an impetus to increase the scope of such activities. In parallel, organizational interventions could be developed to raise awareness of nurses' autonomous motivation. Van DorssenBoog et al. (2021) recently provided evidence that the implementation of a self-leadership training program (based on motivation principles such as mastery, proactive problem-solving, and strengthbased coaching) facilitates healthcare employees' autonomous motivation and fosters their work engagement and performance. Future interventions efforts along these lines are encouraged as they offer promising avenues to foster high quality work motivation and subsequently occupational commitment and retention in nurses. 


\section{References}

Austin, S., Fernet, C., Trépanier, S.-G., \& Lavoie- Tremblay, M. (2020). Fatigue in new registered nurses: A 12- month cross- lagged analysis of its association with work motivation, engagement, sickness absence and turnover intention. Journal of Nursing Management, 28, 606-614.

Baljoon, R.A., Banjar, H., \& Banakhar, M. (2019). Factors affecting nurses' work motivation level at a governmental hospital: A cross-sectional study. Journal of Nursing Education and Practice, 9, $25-35$.

Bass, B.M. (1985). Leadership and performance beyond expectations. Free Press.

Blais, M.R., Lachance, L., Brière, N.M., Dulude, D.M., \& Richer, S. (1991, November). L'inventaire des perceptions du style de supervision au travail. Congrès de la Société Québécoise pour la Recherche en Psychologie, Trois-Rivières, Canada.

Carless, S.A., Wearing, A.J., \& Mann, L. (2000). A short measure of transformational leadership. Journal of Business and Psychology, 14, 389-405.

Cheung, G.W. \& Lau, R.S. (2008). Testing mediation and suppression effects of latent variables: Bootstrapping with structural equation models. Organizational Research Methods, 11, 296-325.

Cummings, G.G., Tate, K., Lee, S., Wong, C.A., Paananen, T., Micaroni, S.P., \& Chatterjee, G.E. (2018). Leadership styles and outcome patterns for the nursing workforce and work environment: A systematic review. International Journal of Nursing Studies, 85, 19-60.

Daouda O.S., Hocine M.N., \& Temime L. (2021). Determinants of healthcare worker turnover in intensive care units: A micro-macro multilevel analysis. PLoS ONE, 16, e0251779.

Duffield, C.M., Roche, M.A., Homer, C., Buchan, J., \& Dimitrelis, S. (2014). A comparative review of nurse turnover rates and costs across countries. Journal of Advanced Nursing, 70, 2703-2712.

Enders, C.K. (2010). Applied missing data analysis. Guilford.

Fernet, C., Morin, A.J.S., Austin, S., Gagné, M., Litalien, D., Lavoie-Tremblay, M., \& Forest, J. (2020). Self-determination trajectories at work: A growth mixture analysis. Journal of Vocational Behavior, 121, 103473.

Fernet, C., Trépanier, S.-G., Austin, S., Gagné, M., \& Forest, J. (2015). Transformational leadership and optimal functioning at work: On the mediating role of employees' perceived job 
characteristics and motivation. Work \& Stress, 29, 11-31.

Fernet, C., Trépanier, S.-G., Demers, M., \& Austin, S. (2017). Motivational pathways of occupational and organizational turnover intention among newly registered nurses in Canada. Nursing Outlook, 65, 444-454.

Gagné, M., \& Deci, E. L. (2005). Self- determination theory and work motivation. Journal of Organizational Behavior, 26, 331-362.

Gagné, M., Forest, J., Vansteenkiste, M., Crevier-Braud, L., Van den Broeck, A., Aspeli, A.K., . . . Güntert, S.T. (2015). The Multidimensional Work Motivation Scale: Validation evidence in seven languages and nine countries. European Journal of Work and Organizational Psychology, 24, 178-196.

Galletta, M., Vandenberghe, C., Portoghese, I., Allegrini, E., Saiani, L., \& Battistelli, A. (2019). A cross- lagged analysis of the relationships among workgroup commitment, motivation and proactive work behaviour in nurses. Journal of Nursing Management, 27, 1148-1158.

Hakanen, J.J., Bakker, A.B., \& Turunen, J. (2021). The relative importance of various job resources for work engagement: A concurrent and follow-up dominance analysis. BRQ Business Research Quarterly, 23409444211012419. Advance online publication.

Hayes, L.J., O’Brien-Pallas, L., Duffield, C., Shamian, J., Buchan, J., Hughes, F., . . North, N. (2012). Nurse turnover: A literature review-an update. International Journal of Nursing Studies, 49, 887-905.

Jungert, T., Schattke, K., Proulx, F.A., Taylor, G., \& Koestner, R. (2020). Whose autonomy support is more effective? Managers' or co- workers'? An experimental comparison of source and occupational context on intrinsic motivation. Canadian Journal of Administrative Sciences. Advance online publication.

Marsh, H.W., Hau, K.-T., \& Grayson, D. (2005). Goodness of fit evaluation in structural equation modeling. In A. Maydeu-Olivares \& J. McArdle (Eds.), Contemporary psychometrics. A festschrift for Roderick P. McDonald (pp. 275-340). Erlbaum.

Meyer, J.P., Allen, N.J., \& Smith, C.A. (1993). Commitment to organizations and occupations: Extension and test of a three-component conceptualization. Journal of Applied Psychology, 78, 
$538-551$.

Muthén, L.K., \& Muthén, B. (2019). Mplus user’s guide. Muthén \& Muthén.

Newman, A., Thanacoody, R., \& Hui, W. (2012). The impact of employee perceptions of training on organizational commitment and turnover: A case of multinationals in the Chinese service sector. Personnel Review, 41, 56-72.

O'Driscoll, M.P., \& Beehr, T.A. (1994). Supervisor behaviors, role stressors and uncertainty as predictors of personal outcomes for subordinates. Journal of Organizational Behavior, 15, 141155.

Perreira, T.A., Berta, W., \& Herbert, M. (2018). The employee retention triad in health care: Exploring relationships amongst organisational justice, affective commitment and turnover intention. Journal of Clinical Nursing, 27, e1451-e1461.

Pursio, K., Kankkunen, P., Sanner- Stiehr, E., \& Kvist, T. (2021). Professional autonomy in nursingAn integrative review. Journal of Nursing Management. Advance online publication.

Reeve, J., \& Cheon, S.H. (2016). Teachers become more autonomy supportive after they believe it is easy to do. Psychology of Sport and Exercise, 22, 178-189.

Ryan, R.M., \& Deci, E.L. (2017). Self-Determination theory: Basic psychological needs in motivation, development, and wellness. Guilford.

Shao, Y., Nijstad, B.A., \& Täuber, S. (2019). Creativity under workload pressure and integrative complexity: The double-edged sword of paradoxical leadership. Organizational Behavior and Human Decision Processes, 155, 7-19.

Sheldon, K.M., \& Elliot, A.J. (1999). Goal striving, need satisfaction, and longitudinal well-being: The self-concordance model. Journal of Personality and Social Psychology, 76, 482-497.

Tett, R.P., \& Meyer, J.P. (1993). Job satisfaction, organizational commitment, turnover intention, and turnover: Path analyses based on meta- analytic findings. Personnel Psychology, 46, 259-293.

Van der Heijden, B.I., Peeters, M.C., Le Blanc, P.M., \& Van Breukelen, J.W.M. (2018). Job characteristics and experience as predictors of occupational turnover intention and occupational turnover in the European nursing sector. Journal of Vocational Behavior, 108, 108-120.

Van Dorssen- Boog, P., van Vuuren, T., de Jong, J.P., \& Veld, M. (2021). Facilitating health care 
workers' self- determination: The impact of a self- leadership intervention on work engagement, health, and performance. Journal of Occupational and Organizational Psychology. Advance online publication.

World Health Organization (2020). Nursing and midwifery. Retrieved March 10 2021, from https://www.who.int/fr/news-room/fact-sheets/detail/nursing-and-midwifery. 
Table 1

Latent Correlations Between the Variables

\begin{tabular}{|c|c|c|c|c|c|c|c|c|}
\hline Variable & 1 & 2 & 3 & 4 & 5 & 6 & 7 & 8 \\
\hline 1. Autonomous motivation (T1) & - & & & & & & & \\
\hline 2. Occupational commitment (T1) & .588 & - & & & & & & \\
\hline 3. Occupational turnover intention (T1) & -.330 & -.733 & - & & & & & \\
\hline 4. Supportive supervisor behaviors (T1) & .346 & .279 & -.202 & - & & & & \\
\hline 5. Supportive coworker behaviors (T1) & .571 & .418 & -.366 & .352 & - & & & \\
\hline 6. Autonomous motivation (T2) & .778 & .511 & -.438 & .269 & .540 & - & & \\
\hline 7. Occupational commitment (T2) & .647 & .944 & -.729 & .340 & .471 & .682 & - & \\
\hline 8. Occupational turnover intention (T2) & -.392 & -.590 & .684 & -.224 & -.439 & -.511 & -.667 & - \\
\hline
\end{tabular}


Table 2

Standardized Factor Loadings $(\lambda)$ and Uniquenesses $(\delta)$ for the Measurement Model

\begin{tabular}{|c|c|c|c|c|}
\hline \multirow[b]{2}{*}{ Items } & \multirow{2}{*}{$\begin{array}{c}\text { Time } 1 \\
\lambda\end{array}$} & \multicolumn{3}{|c|}{ Time 2} \\
\hline & & $\delta$ & $\lambda$ & $\delta$ \\
\hline \multicolumn{5}{|c|}{ Autonomous motivation } \\
\hline Item 1 & .647 & .582 & .617 & .619 \\
\hline Item 2 & .389 & .849 & .471 & .778 \\
\hline Item 3 & .479 & .770 & .603 & .636 \\
\hline Item 4 & .857 & .266 & .859 & .262 \\
\hline Item 5 & .834 & .305 & .917 & .159 \\
\hline Item 6 & .823 & .323 & .842 & .291 \\
\hline$\omega$ & .840 & & .871 & \\
\hline \multicolumn{5}{|c|}{ Occupational commitment } \\
\hline Item 1 & .837 & .300 & .617 & .620 \\
\hline Item 2 & .765 & .415 & .766 & .413 \\
\hline Item 3 & .754 & .431 & .839 & .296 \\
\hline$\omega$ & .829 & & .788 & \\
\hline \multicolumn{5}{|c|}{ Occupational turnover intention } \\
\hline Item 1 & .855 & .269 & .836 & .301 \\
\hline Item 2 & .779 & .392 & .932 & .132 \\
\hline Item 3 & .937 & .122 & .941 & .115 \\
\hline$\omega$ & .894 & & .931 & \\
\hline \multicolumn{5}{|c|}{ Supportive supervisor behaviors } \\
\hline Item 1 & .747 & .443 & & \\
\hline Item 2 & .868 & .247 & & \\
\hline Item 3 & .869 & .244 & & \\
\hline Item 4 & .920 & .154 & & \\
\hline Item 5 & .803 & .356 & & \\
\hline Item 6 & .793 & .371 & & \\
\hline Item 7 & .876 & .232 & & \\
\hline$\omega$ & .944 & & & \\
\hline \multicolumn{5}{|c|}{ Supportive coworker behaviors } \\
\hline Item 1 & .740 & .453 & & \\
\hline Item 2 & .859 & .262 & & \\
\hline Item 3 & .574 & .670 & & \\
\hline$\omega$ & .773 & & & \\
\hline
\end{tabular}

Note. $\lambda$ : Factor loading; $\delta$ : Item uniqueness; $\omega$ : Omega coefficient of model-based composite reliability; non-significant parameters $(p>.05)$ are marked in italics. 


\section{Figure 1}

The Final Model

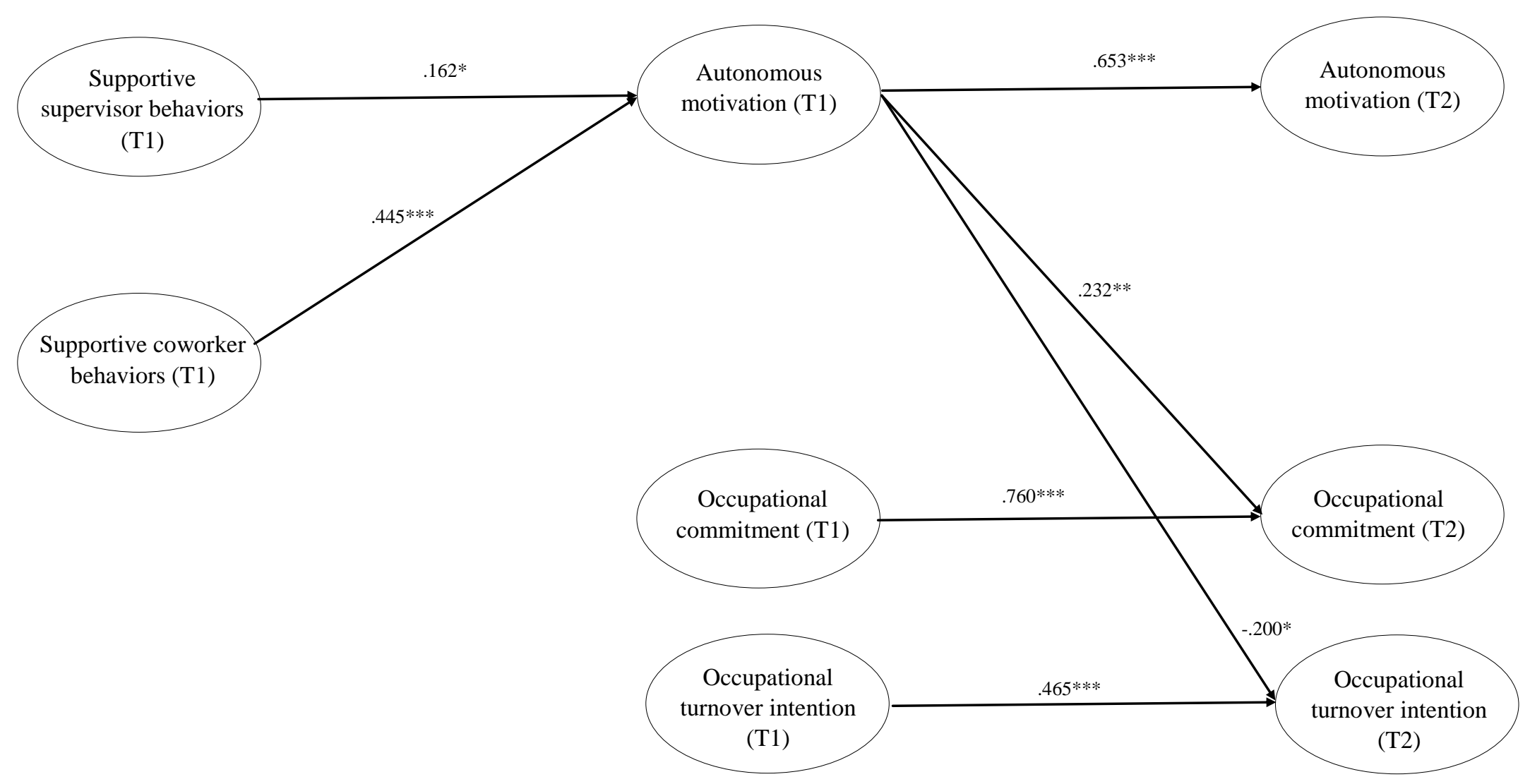

Note. $* p<.05, * * p<.01, * * * p<.001$; for clarity purposes, covariances and indicators of latent variables are not presented. 